\title{
Self-Administered Mepolizumab in the Management of Severe Asthma: Usability and Patient Acceptance
}

This article was published in the following Dove Press journal: Patient Preference and Adherence

\author{
Reika Miyokawa' \\ Celeste Kivler' \\ Samuel Louie \\ Dorottya Godor ${ }^{2}$ \\ Laren Tan (D) $^{3}$ \\ Nicholas Kenyon ${ }^{1,4}$ \\ 'Division of Pulmonary, Critical Care and \\ Sleep Medicine, Department of Internal \\ Medicine, University of California Davis, \\ Sacramento, CA 958I7, USA; \\ ${ }^{2}$ Northwick Park Hospital London North \\ West University Healthcare NHS Trust \\ Watford Road, London HAI 3UJ, UK; \\ ${ }^{3}$ Division of Pulmonary \& Critical Care \\ Medicine, Department of Internal \\ Medicine, School of Medicine Loma Linda \\ University, Loma Linda, CA 92354, USA; \\ ${ }^{4} V A$ Northern California Health Care \\ System, Mather, CA 95655, USA
}

\begin{abstract}
The increasing use of advanced biologic therapies for patients with severe asthma is transforming the standard of care, clinic workflow, and the clinic business model. Expanded patient access to at-home injection treatment possibilities with some biologics has the potential to improve patient adherence and outcomes. Simultaneously, transition to the home setting can address the escalating costs that limit access for certain patients and healthcare facilities. Such moves come with recognized risks. Garnering input from physicians and other healthcare specialists as well as scrutinizing best practice position statements are vital to implementing truly patient-safe and cost-effective strategies in medicine. Mepolizumab is the first anti-IL-5 inhibitor to receive FDA approval in late 2015. We focus on this injectable medication and discuss the specific indications and contraindications for transitioning patients to at-home injection with mepolizumab. In doing so, we review our recent real-world experiences in the University of California, Davis and Loma Linda University severe asthma clinics, which can provide the foundation for building a comprehensive clinic and home-based biologics asthma program. In addition, we offer insight into the barriers to implementing a successful program and strategies for overcoming them.
\end{abstract}

Keywords: asthma, mepolizumab, home administration, best practice

\section{Introduction}

Asthma is a chronic respiratory disease with a female predominance, affecting an estimated $10.0 \%$ of adult women in the US and about $5.5 \%$ having suffered an asthma attack in the past year. ${ }^{1}$ Risk of developing asthma varies by region. In the Central Valley of California, for example, the lifetime risk of asthma in children approaches $25 \%$ in certain counties. ${ }^{2}$ Most of the annual costs for asthma are incurred by the $5-10 \%$ of patients with severe asthma. ${ }^{3}$ With the advent of novel biological therapies that can be self-administered at home, it is possible that less resources and costs will be attributed to the care of patients with severe asthma. Certainly, this will be of interest to health economists and society will look closely on whether these medications decrease or increase total costs. ${ }^{3}$ It is imperative that we comprehend the global impact of these new treatments, especially in the most vulnerable and susceptible populations.

Since asthma is a complex, heterogeneous disease, efforts to personalize the management of asthma have become more structured. Understandably, there has been a focus on novel biologic medications that target specific cytokines that in part define asthma endotypes. In regards to understanding the need for biologics, the split
Correspondence: Nicholas Kenyon Division of Pulmonary, Critical Care and Sleep Medicine University of California

Davis, 4I50 V Street, Suite 3400,

Sacramento, CA 95816, USA

Tel + I 916-734-3564

Email njkenyon@ucdavis.edu
Patient Preference and Adherence 2020:14 1669-1682

1669

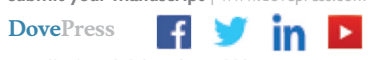

http://doi.org/| 0.21 47/PPA.S227465 
into T2-low and T2-high inflammatory endotypes remain most salient. ${ }^{4}$ Five to ten percent asthmatics may benefit from endotyping with a goal of starting biologic therapies. ${ }^{5}$ Potential barriers include clinical and financial restraints in coordination, integration and resources for advanced asthma controller treatments. In this article, we will focus our review on the opportunities for treating patients with severe asthma with mepolizumab and present a framework for understanding the management such patients in the office and at home.

\section{Rationale for Novel Biologics}

For longer than a generation, clinicians have practiced asthma care by grouping asthma into two large patient groups: allergic or extrinsic asthma, and non-allergic or intrinsic asthma. ${ }^{6}$ This has changed over the past 10 to 20 years with an improved understanding of the pathophysiology. For example, one seminal study by Woodruff and colleagues triggered a discussion about regrouping asthma phenotypes and biomarkers. ${ }^{6}$ They outlined a "Th2 high" and Th2 low group based on IgE levels, lung and peripheral blood eosinophil counts, aeroallergen skin prick test counts, and airway epithelial cell gene expression levels for MUC5AC and others. ${ }^{6}$ This study was one of the first to show clear responses to inhaled corticosteroid (ICS) therapy tailored to a specific phenotype in severe asthmatics. ${ }^{6}$ Since then, clinical research and the advent of biologics have made phenotyping and endotyping asthma patients who are not readily controlled on ICS after three to four months a mandate for patient safety and pharmacoeconomics. At the core of this approach is the need for clinicians to recognize that asthma is a syndrome and is heterogeneous in its severity as well its response to treatment(s). Phenotyping can remove a great deal of the guesswork in selecting advanced treatments to better control a patient's symptoms and reduce risk for acute exacerbations. However, this requires time (approximately three months) and patience to observe the response to initial treatment. Global initiative for asthma (GINA) in their 2017 update has recommended beginning all patients on low-dose ICS plus a leukotriene receptor antagonist (LTRA) (Figure 1, step 2) and to retrospectively determine asthma control and severity or a failure to respond to therapy as the guide to stepping up treatments to those such as ICS plus LABA (Figure 1, step $3)^{7,8}$ This strategy, updated in 2020 , remains challenging because a significant number of patients with asthma do not respond to ICS, and they still may not respond to low-dose ICS when a LABA is added in a fixed combination inhaler. ${ }^{8,9}$ This carries the risk of exposing patients to the myriad of adverse effects of corticosteroids with none of the benefits.

\section{Mechanism of Mepolizumab}

Mepolizumab is a humanized IgG1 kappa monoclonal antibody against interleukin-5 (IL-5) (Figure 2). ${ }^{10}$ In the United States, it was approved for use by the Federal Drug Administration in 2015 as an add-on maintenance therapy for severe eosinophilic asthma. ${ }^{11}$ Several cytokines, including IL-4, IL-5, and IL-13 play a major role in the pathophysiology of type 2 inflammation and eosinophilic asthma. ${ }^{12,13}$ Of these, IL-5 is especially crucial for differentiation and survival of eosinophils. ${ }^{14}$ IL-5 is mainly produced by $\mathrm{Th} 2$ cells, but also in lesser quantities by eosinophils in an autocrine manner and by paracrine sources including mast cells, basophils, natural killer cells, and innate lymphoid cells. ${ }^{15}$ IL-5 binds to IL-5 receptors (IL5R). ${ }^{15}$ The receptor consists of an alpha chain that is specific to IL-5 binding and a common beta unit that facilitates signaling, which also binds to other cytokines such as granulocyte-macrophage colony-stimulating factor (GMCSF) and IL-3. ${ }^{15}$ IL5Rs are selectively expressed on eosinophils and basophil cell membranes, although they are expressed three times as much on eosinophils than on basophils. $^{12,15}$

During hematopoiesis, IL-5 binds to IL5R to promote terminal differentiation of progenitor cells into mature eosinophils. ${ }^{14}$ IL-5 also facilitates integrin-mediated adhesion of eosinophils to allow for their migration out of the bone marrow into the peripheral circulation, and eventually to the local inflammatory site. ${ }^{16}$ In the bloodstream and at the inflammatory sites, IL-5 mediated signaling also lead to decreased apoptosis and thus increased eosinophil counts. ${ }^{16}$ Mepolizumab inhibits IL-5, decreasing its binding to IL5R. Selective antagonization of IL-5 results in reduced maturation, recruitment, and survival of eosinophils. The ultimate effect is therefore a decrease in 1) an immunological cascade that leads to further chemoattraction of inflammatory cells, 2) eosinophil-mediated parasympathetic response and airway hyperresponsiveness, and 3) airway remodeling, which are all factors that contribute to enhanced asthmatic symptoms. ${ }^{17}$ As a result, clinical trials have shown that mepolizumab use decreases exacerbation rates and improves baseline symptomatic control when used as maintenance therapy. ${ }^{18}$ These findings prompted the development of IL-5-neutralizing monoclonal antibodies (mAbs). 


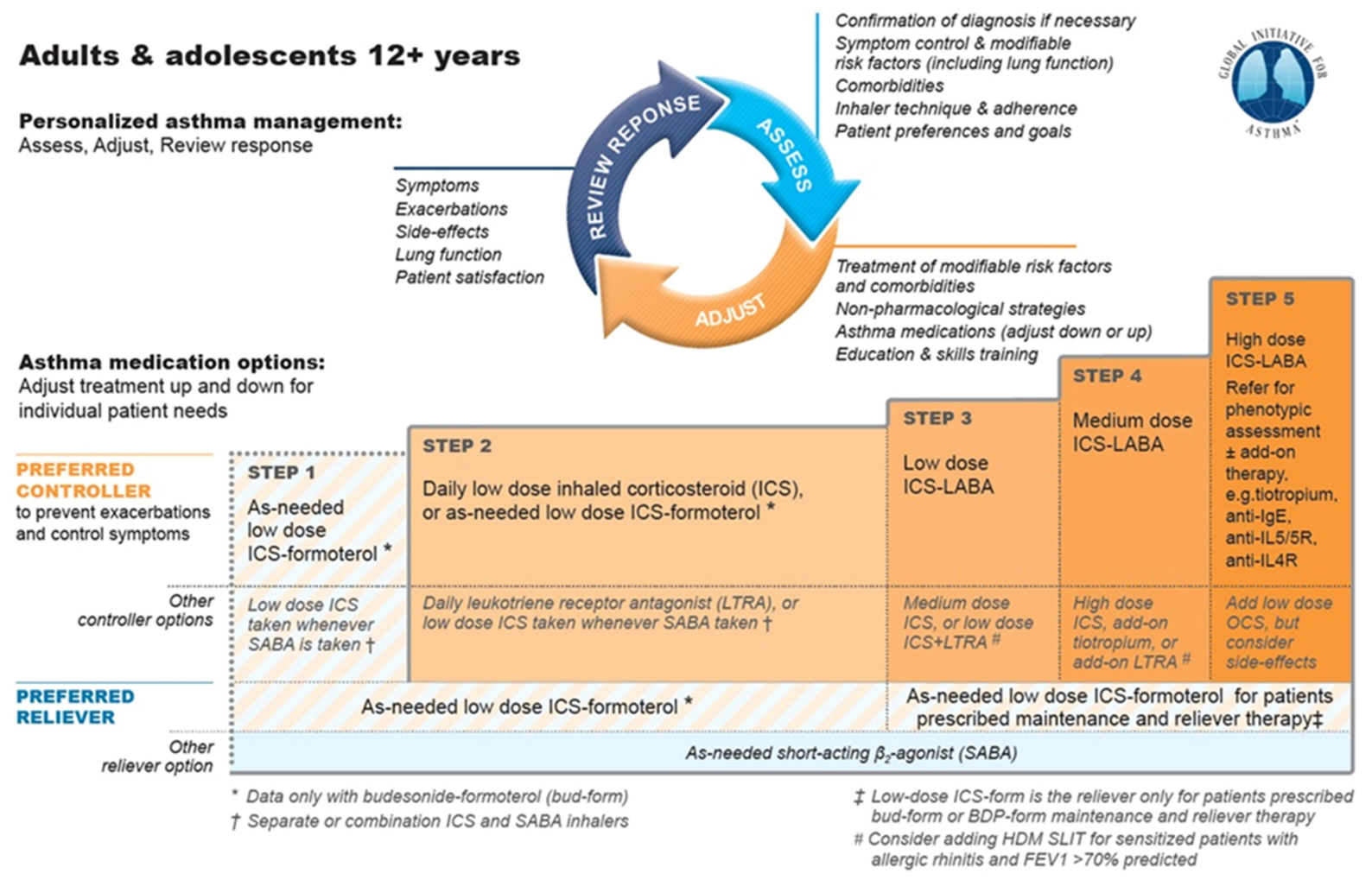

Figure I Medication options for asthma.

Notes: @2020 Global Initiative for Asthma, reprinted with permission. Available from www.ginasthma.org. ${ }^{8}$

Abbreviations: ICS, inhaled corticosteroid; SABA, short-acting beta2-agonist; LTRA, leukotriene receptor antagonist; LABA, long-acting beta2-agonist; IgE, immunoglobulin E; IL5, interleukin 5; IL5R, interleukin 5 receptor; IL4R, interleukin 4 receptor; OCS, oral corticosteroid.

Other monoclonal antibodies that target IL-5 include reslizumab and benralizumab. Reslizumab works similarly as a monoclonal IL-5 antagonist, however, binds to a different epitope. $^{12,15}$ Benralizumab is an IL-5 receptor alpha (IL5R $\alpha$ ) chain antagonist, which works by reducing IL-5 binding as well as through antibody-dependent cellmediated cytotoxicity (Figure 2). ${ }^{15}$ Mepolizumab (Nucala, GlaxoSmithKline) is the first-in-class monoclonal antibody that targets IL-5. First approved by the FDA in June 2015, at present it is used for severe eosinophilic asthma as an addon maintenance treatment both in adults and children over the age of 6. This makes mepolizumab in the United States the only targeted biologic approved for severe asthma in the pediatric population. It is also approved in the United States as add-on maintenance treatment for patients with ChurgStrauss Syndrome. ${ }^{11}$ Mepolizumab is currently being investigated for several other indications. As per Phase 3 studies, mepolizumab was associated with a lower annual rate of moderate or severe exacerbations than placebo among patients with chronic obstructive pulmonary disease (COPD) and an eosinophilic phenotype. ${ }^{19}$ It is also the first therapy capable of reducing flares in patients with hypereosinophilic syndrome, ${ }^{20}$ and the first anti-IL5 biologic to report positive phase 3 results in patients with nasal polyps. $^{21}$

\section{The Efficacy of Mepolizumab in Severe Eosinophilic Asthma in Clinical Trials}

A comprehensive clinical trial program investigated the efficacy of mepolizumab which consisted of 4 randomized, double-blind, parallel-group clinical studies of between 24 and 52 weeks duration (Figure 3). The dose-ranging efficacy study DREAM $^{23}$ and the exacerbation reduction study MENSA $^{24}$ were complemented by SIRIUS, ${ }^{18}$ an oral corticosteroid-sparing study, and MUSCA, ${ }^{25}$ a quality-of-life study. The study patients were aged 12 years and older, and had severe refractory eosinophilic asthma. The latter means that they remained uncontrolled ( $2 \leq$ severe exacerbations in the previous 12 months) on their current standard of care, including at least high-dose ICS plus LABA, LTRA, long-acting muscarinic antagonists (LAMA), or theophylline, or were dependent on 


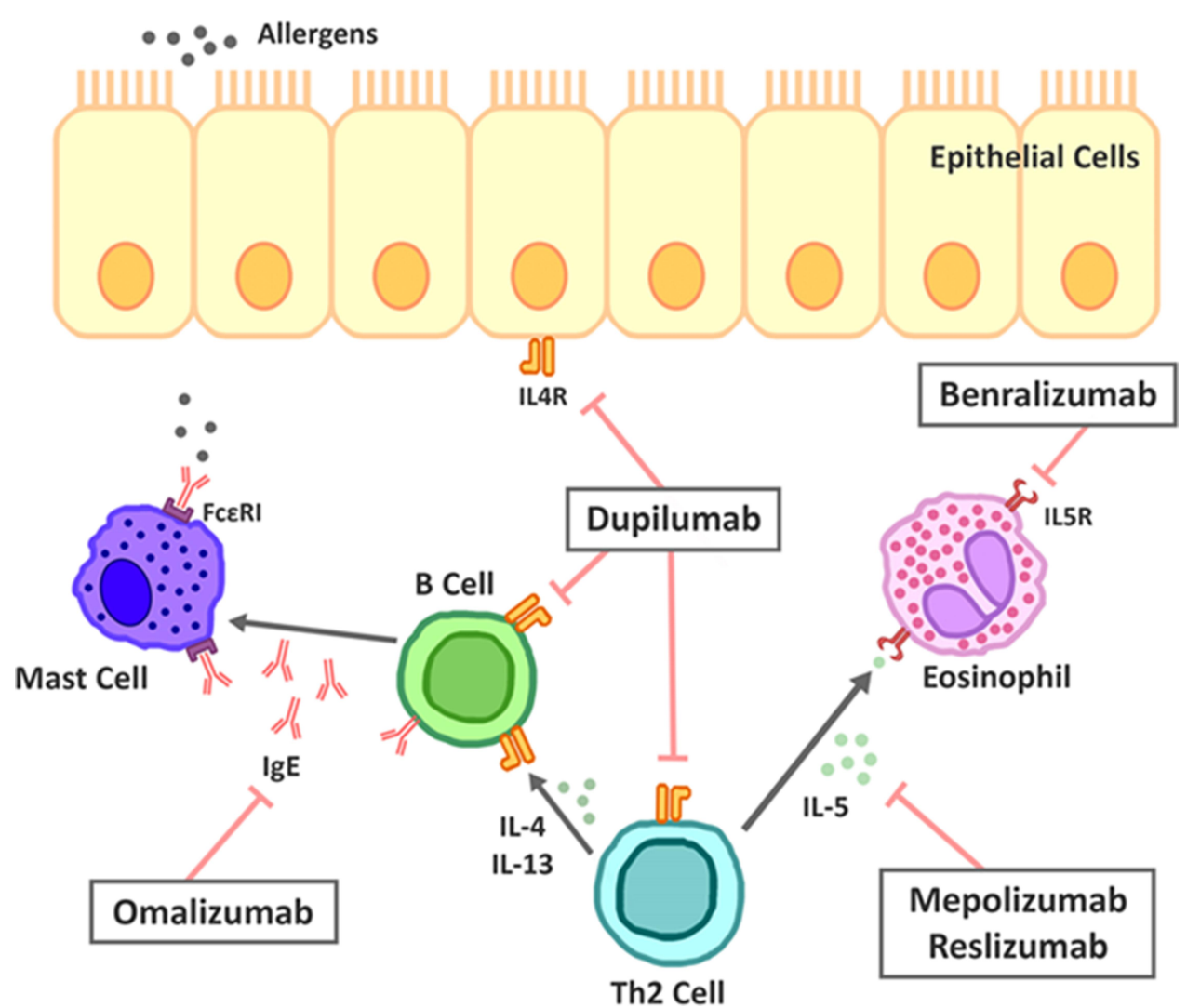

Figure 2 Therapeutic targets for biologics in severe asthma.

Notes: Adapted from Fajt ML, Wenzel SE. Development of New Therapies for Severe Asthma. Allergy Asthma Immunol Res. 2017;9(I):3-14.22 Mepolizumab and reslizumab are monoclonal antibodies that antagonize IL-5, whereas benralizumab inhibits the alpha unit of IL-5 receptors. Dupilumab targets the alpha unit of IL4 receptors, and omalizumab targets circulating lgE.

Abbreviations: IL-5, interleukin 5; IL5R, interleukin 5 receptor; IL-4, interleukin 4; IL4R, interleukin 4 receptor; IL-I3, interleukin I3; IgE, immunoglobulin E; Fc\&RI, highaffinity IgE receptor; Th2 cell, $T$ helper type 2 cells.

\section{Overview of Clinical Trials with Mepolizumab in the Treatment of Severe Eosinophilic Asthma}

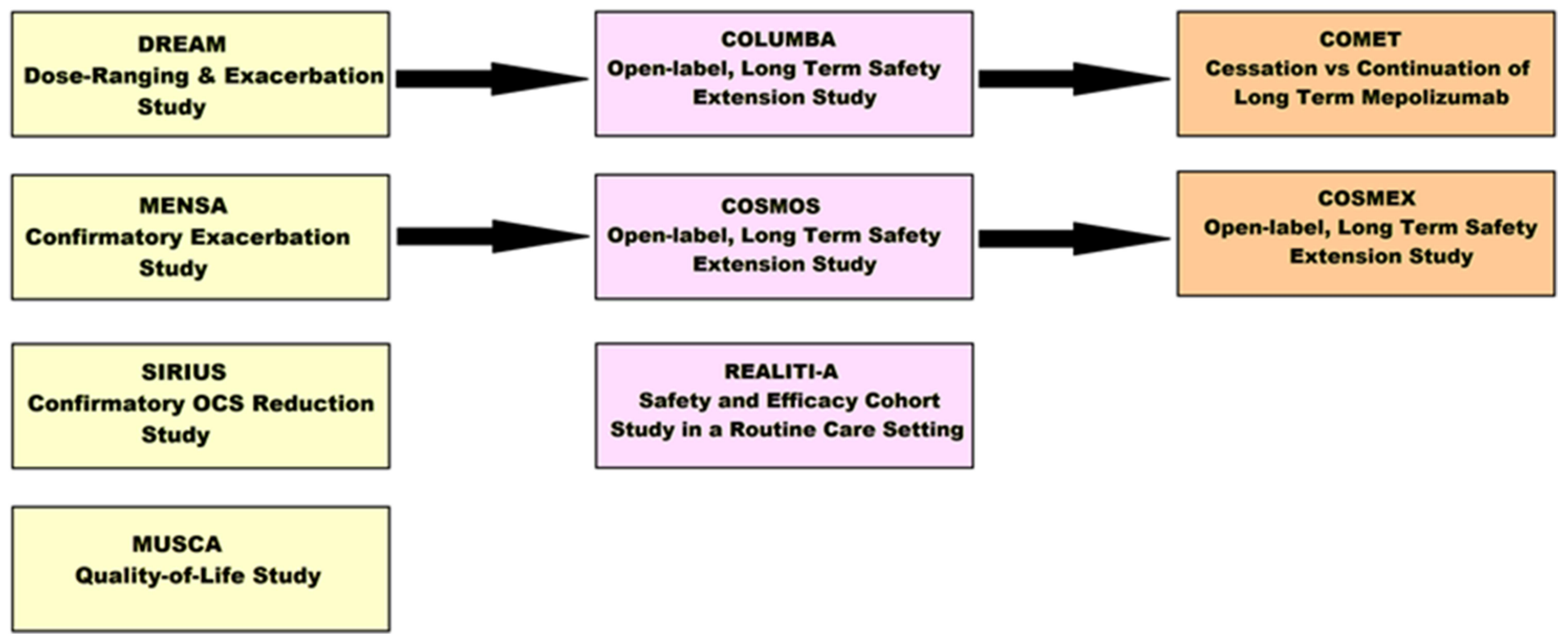

Figure 3 Overview of Clinical Trials with Mepolizumab in the Treatment of Severe Eosinophilic Asthma. Abbreviation: OCS, oral corticosteroid. 
systemic corticosteroids. Patients continued to receive their existing asthma medicine during the studies.

In the Phase II trial DREAM, patients in the intravenous (IV) mepolizumab-treated arms (75, 250, and $750 \mathrm{mg}$ ) demonstrated statistically significant reductions in asthma exacerbations by $48 \%, 39 \%$, and $52 \%$, respectively, relative to placebo. ${ }^{23}$

In the subsequent Phase III exacerbation reduction study MENSA, subcutaneous (SC) and IV mepolizumab reduced annualized exacerbation rates by $47 \%$ and $53 \%$ each, relative to placebo. The SC dose reduced hospitalizations by $69 \%$, and ED visits and hospital admissions by $61 \%$. Sixty-seven percent of patients in the mepolizumab arm had zero exacerbations. ${ }^{24}$

Post hoc analysis combining the DREAM and MENSA studies revealed a trend of greater reduction in exacerbations with increasing baseline blood eosinophil count. ${ }^{24}$

Mepolizumab was associated with significant improvements in health status in patients with severe eosinophilic asthma, as demonstrated by the phase IIIb quality-of-life study, MUSCA. ${ }^{25}$

Next, SIRIUS, ${ }^{18}$ a phase III OCS reduction study evaluated the effect of SC mepolizumab on reducing the requirement for maintenance OCS while maintaining asthma control in subjects with severe refractory eosinophilic asthma. The patients were on a baseline mean prednisone equivalent dose of approximately $13 \mathrm{mg}$ /day, ranging from $5 \mathrm{mg}$ to $35 \mathrm{mg}$. During an optimization period, patients were brought down to the lowest possible levels of OCS to keep their asthma well controlled. Patients receiving doses of $20 \mathrm{mg}$ /day or less of prednisone at the end of the optimization phase were eligible to wean completely off steroids. This study showed a powerful $50 \%$ median reduction in OCS use from baseline compared with no change $(0 \%)$ in placebo while maintaining asthma control. That is, patients in the mepolizumab group reduced their steroid dose from a median dose of $10 \mathrm{mg} /$ day down to $5 \mathrm{mg} /$ day.

The real-world effectiveness of mepolizumab in severe eosinophilic asthma patients in a routine care setting is currently being studied in a two-year, global, prospective, single-arm, observational cohort study called REALITIA. ${ }^{26}$ The interim analysis has reported a $69 \%$ reduction in the annual rate of clinically significant exacerbations and a $77 \%$ reduction in the annual rate of exacerbations requiring hospitalization or emergency room visits. A significant reduction was also observed in median OCS dose from $10 \mathrm{mg} /$ day to $5 \mathrm{mg}$ /day, with $34 \%$ of patients able to discontinue oral corticosteroid use completely. The full results of this study are expected to be released in 2021 .

COLUMBA, $^{27}$ a 4.5 year-long extension study to DREAM, investigated the long-term safety and efficacy of mepolizumab. As much as $33 \%$ of patients had no exacerbations on long-term treatment with mepolizumab, and $53 \%$ had $\leq 1$ exacerbations over 4.5 years despite entering the study with an average of almost two exacerbations (1.74) per year. It also showed a $61 \%$ decrease in exacerbation rate. Mepolizumab achieved a $78 \%$ reduction in blood eosinophils from a mean baseline blood eosinophil level of 240 cells $/ \mu \mathrm{L}$ by week 4 and sustained this over the study period. An improvement in asthma control was seen by week 12 and was maintained until the end of the 4.5-year-long study. The initial improvement in lung function gradually eased over the study period, reflecting the overall decline in lung function seen in patients with severe asthma. ${ }^{27,28}$

An extension study to COLUMBA, COMET ${ }^{29}$ examined outcomes after continuing or stopping mepolizumab following long-term continuous treatment on mepolizumab. Patients who stopped mepolizumab had an increase in blood eosinophil count, an increase in exacerbations, a shorter time to first exacerbation, and a reduction in asthma control versus those who continued mepolizumab. Long-term treatment with mepolizumab in the COSMEX study $^{30}$ provided sustained and consistent exacerbation and OCS reductions for up to 4.5 years with additional patients no longer requiring oral steroids.

\section{Reported Adverse Effects of Mepolizumab}

In DREAM, MENSA and SIRIUS, about $2 \%$ of patients receiving mepolizumab withdrew from the clinical trials due to adverse events, compared with $3 \%$ of patients in the placebo arm (Table 1). The most commonly reported adverse reactions during treatment were headache (19\%), local injection site reactions $(8 \%)$ back pain $(5 \%)$ and fatigue $(5 \%)$. In the above trials, $3 \%$ of patients experienced influenza, urinary tract infection, upper abdominal pain, pruritus and eczema, respectively. Systemic reactions occurred in 3\% of patients and manifested in rash, flushing, pruritus, headache and myalgia, mostly on the day of dosing. Acute and delayed systemic reactions, including hypersensitivity reactions (eg, anaphylaxis, urticaria, angioedema, urticaria, rash, bronchospasm, hypotension) occurred in $2 \%$ of patients, mostly within hours of administration, but in some instances later, in several days. Herpes zoster occurred in 2 patients as 
Table I Reported Adverse Events with Asthma Biologics

\begin{tabular}{|c|c|c|c|c|c|}
\hline & Omalizumab & Mepolizumab & Reslizumab & Benralizumab & Dupilumab \\
\hline Anaphylaxis warning & $\begin{array}{l}\text { Yes, } 0.1 \% \text { as early as first dose premarketing } \\
\text { and at least } 0.2 \% \text { post- marketing }\end{array}$ & No, but reported & $\begin{array}{l}\text { Yes, } 0.3 \% \text { and } \\
\text { as early as } \\
\text { the second } \\
\text { dose }\end{array}$ & $\begin{array}{l}\text { No, but } \\
\text { reported }\end{array}$ & $\begin{array}{l}\text { No, but } \\
\text { reported }\end{array}$ \\
\hline $\begin{array}{l}\text { Epinephrine injectable } \\
\text { required }\end{array}$ & Yes & No, or physician decision & Yes & $\begin{array}{l}\text { No, or } \\
\text { physician } \\
\text { decision }\end{array}$ & $\begin{array}{l}\text { No, or } \\
\text { physician } \\
\text { decision }\end{array}$ \\
\hline Pregnancy category & B & $?$ & $?$ & $?$ & $?$ \\
\hline $\begin{array}{l}\text { Injection site reaction, } \\
\text { ie pain, erythema, } \\
\text { itching, swelling, burning }\end{array}$ & $45 \%$ vs $43 \%$ with placebo & $8 \%$ vs $3 \%$ with placebo & Not reported & $\begin{array}{l}2.2 \% \text { vs } 1.9 \% \\
\text { with placebo }\end{array}$ & $\begin{array}{l}18 \% \text { vs } 6 \% \\
\text { with placebo }\end{array}$ \\
\hline Headache & $15 \%$ and similar to placebo & $19 \%$ vs $18 \%$ with placebo & Not reported & $\begin{array}{l}8 \% \text { vs } 6 \% \text { with } \\
\text { placebo }\end{array}$ & $\begin{array}{l}\text { Not } \\
\text { reported }\end{array}$ \\
\hline $\begin{array}{l}\text { Pharyngitis or } \\
\text { oropharyngeal pain }\end{array}$ & II\% and similar to placebo & $<3 \%$ & $\begin{array}{l}2.6 \% \text { vs } 2.2 \% \\
\text { with placebo }\end{array}$ & $\begin{array}{l}5 \% \text { vs } 3 \% \text { with } \\
\text { placebo }\end{array}$ & $\begin{array}{l}2 \% \text { vs } 1 \% \\
\text { with placebo }\end{array}$ \\
\hline $\begin{array}{l}\text { Hypersensitivity } \\
\text { reactions }^{\S}\end{array}$ & Moderate to Severe Persistent & $3 \%$ vs $3 \%$ with placebo & $\begin{array}{l}\text { Reported with } \\
\text { anaphylaxis }\end{array}$ & $\begin{array}{l}3 \% \text { vs } 3 \% \text { with } \\
\text { placebo }\end{array}$ & $\begin{array}{l}<1 \% \text { in } \\
\text { clinical trials }\end{array}$ \\
\hline Fever & See Notes below & Not reported & Not reported & $\begin{array}{l}3 \% \text { vs } 2 \% \text { with } \\
\text { placebo }\end{array}$ & $\begin{array}{l}\text { Not } \\
\text { reported }\end{array}$ \\
\hline $\begin{array}{l}\text { Blood eosinophils } \geq \\
3000 \text { cell } / \mu \mathrm{L}\end{array}$ & Not reported & Not reported & Not reported & Not reported & $\begin{array}{l}2 \% \text { vs }<1 \% \\
\text { with placebo }\end{array}$ \\
\hline $\begin{array}{l}\text { Parasites (Helminth) } \\
\text { infection* }\end{array}$ & $53 \%$ vs $42 \%$ with placebo in Brazil & Caution, no cases reported & $\begin{array}{l}\text { Caution, no } \\
\text { cases } \\
\text { reported }\end{array}$ & $\begin{array}{l}\text { Caution, no } \\
\text { cases reported }\end{array}$ & $\begin{array}{l}\text { Caution, no } \\
\text { cases } \\
\text { reported }\end{array}$ \\
\hline Other & Malignancy $0.5 \%$ vs $0.2 \%$ with placebo $\pi$ & $\begin{array}{l}2 \text { serious Herpes zoster reactions } \\
\text { occurred vs none with placebo. } \\
\text { Consider prior vaccination }\end{array}$ & $\begin{array}{l}\text { Malignancy } \\
0.6 \% \text { vs } 0.3 \% \\
\text { with placebo }\end{array}$ & $\begin{array}{l}\text { Risk of cancer } \\
\text { unknown }\end{array}$ & $\begin{array}{l}\text { Risk of } \\
\text { cancer } \\
\text { unknown }\end{array}$ \\
\hline Notes & $\begin{array}{l}\text { Churg- Strauss syndrome reported }{ }^{f} \text { With } \\
\text { fever }+ \text { arthralgia }+ \text { rash }+ \text { lymph nodes }=\text { ? } \\
\text { serum sickness }=\text { STOP treatment }\end{array}$ & $\begin{array}{l}\text { Indicated for treatment of Churg- } \\
\text { Strauss syndrome at dosage of } \\
300 \mathrm{mg} \mathrm{SC} \text { every } 4 \text { weeks }\end{array}$ & & & \\
\hline
\end{tabular}

Notes: Direct comparison of adverse events between biologics is invalid for assessment of safety or medical decision-making. Only comparison to placebo in each biologic is valid. ${ }^{\S}$ Hypersensitivity reactions may include skin rash, urticaria, angioedema, and/or bronchospasm. For mepolizumab, hypotension and anaphylaxis was included in the Prescribing Information as a hypersensitivity reaction. *Treat patients with pre-existing helminth infections before initiating therapy with a biologic. If patients become infected while receiving treatment with biologic and do not respond to anti-helminth treatment, discontinue treatment with biologic until infection resolves. "In a subsequent observational study of 5007 omalizumab-treated and 2829 non- omalizumab-treated adolescent and adult patients with moderate to severe persistent asthma and a positive skin test reaction or in vitro reactivity to a perennial aeroallergen, patients were followed for up to 5 years. In this study, the incidence rates of primary malignancies (per 1000 patient years) were similar among omalizumab-treated (12.3) and non-omalizumab-treated patients (13.0) [see Adverse Reactions (6)]. However, study limitations preclude definitively ruling out a malignancy risk with omalizumab. Study limitations include: the observational study design, the bias introduced by allowing enrollment of patients previously exposed to omalizumab (88\%), enrollment of patients $(56 \%)$ while a history of cancer or a premalignant condition were study exclusion criteria, and the high study discontinuation rate (44\%). ${ }^{\epsilon}$ In rare cases, patients with asthma on therapy with omalizumab may present with serious systemic eosinophilia sometimes presenting with clinical features of vasculitis consistent with Churg-Strauss syndrome, a condition which is often treated with systemic corticosteroid therapy. These events usually, but not always, have been associated with the reduction of OCS therapy. Physicians should be alert to eosinophilia, vasculitic rash, worsening pulmonary symptoms, cardiac complications, and/or neuropathy presenting in their patients. A causal association between omalizumab and these underlying conditions has not been established. ? indicates unknown. Data from Fajt and Wenzel. ${ }^{22}$

Abbreviations: SC, subcutaneous: OCS, oral corticosteroid.

a serious adverse event; therefore, it is advisable to consider vaccination if appropriate. $^{31}$

The safety profile of mepolizumab in severe refractory eosinophilic asthma patients in open-label extension studies such as COLUMBA, COSMOS, and COSMEX in the course of a median of 2.8 years of treatment (range 4 weeks to 4.5 years) was similar to that observed in the placebo-controlled studies.

The long-term safety and efficacy of mepolizumab in patients with severe eosinophilic asthma was evaluated in 
the long-term open-label extension study COLUMBA, ${ }^{31}$ the longest study of an anti-IL5 biologic treatment in severe eosinophilic asthma to be reported. COLUMBA was an extension study to DREAM, where mepolizumab was added to standard care for an average of 3.5 years and a maximum of 4.5 years. The safety and immunogenicity profile of mepolizumab was similar to previous clinical studies, with no new safety concerns identified. In COLUMBA, on-treatment adverse events were reported in $94 \%$ of patients, of which the most frequently reported were viral upper respiratory tract infection (49\%), headache $(29 \%)$, asthma worsening $(27 \%)$, bronchitis $(21 \%)$. Serious adverse events occurred in $23 \%$ of patients, who experienced asthma (10\%) and pneumonia (2\%). Eight participants (2\%) developed allergic/hypersensitivity reactions, although none met diagnostic criteria for anaphylaxis. Eight subjects $(2 \%)$ experienced a herpes zoster infection. There were 6 deaths, none of which were assessed as related to mepolizumab. Anti-drug antibodies were detected in $8 \%$ of patients, with no neutralizing antibodies, and no impact on blood eosinophil level or the pharmacokinetics and pharmacodynamics of mepolizumab, consistent with the immunogenicity profile from previous studies. ${ }^{27}$

While there has been studies that show that mepolizumab may decrease oral glucocorticoid requirements, patients should not abruptly discontinue steroid use with initiation of mepolizumab. ${ }^{11}$ It should be also noted that mepolizumab is not indicated for use as acute therapy for bronchospasm or status asthmaticus. ${ }^{11}$

Although no parasitic infections were reported in the clinical studies with mepolizumab, for all the new biologics affecting eosinophils, there is a theoretical risk of interference with the immunological response to helminth infections. Treatment of existing helminth infections is advised. If the patient becomes infected while on treatment, the temporary discontinuation of therapy might be necessary. ${ }^{31}$

Single doses of up to $1500 \mathrm{mg}$ were administered intravenously in a clinical trial to patients with eosinophilic disease without evidence of dose-related toxicities. There is no specific treatment for an overdose with mepolizumab. If overdose occurs, the patient should be treated supportively with appropriate monitoring as necessary. ${ }^{31}$

In terms of interaction with other drugs, cytochrome P450 enzymes, efflux pumps and protein-binding mechanisms are not involved in the clearance of mepolizumab. The potential for interactions with mepolizumab is therefore considered low. ${ }^{31}$
Monoclonal antibodies do cross the placenta, particularly in the $2 \mathrm{nd}$ and $3 \mathrm{rd}$ trimester. ${ }^{32}$ Therefore, pregnant women were excluded from the studies, and women of childbearing age were required to use effective birth control. This is why only a limited amount of data (less than 300 pregnancy outcomes) is available from the use of mepolizumab in pregnant women, and its potential for causing fetal harm is not known. No data exist regarding the excretion of mepolizumab in human milk either. In monkeys, mepolizumab was shown to cross the placental barrier and was shown to be excreted into the milk of monkeys at concentrations of less than $0.5 \%$ of those detected in plasma. Although animal studies did not indicate any reproductive toxicity, it is preferable to avoid the use of mepolizumab during pregnancy and breastfeeding. ${ }^{32}$ A pregnancy exposure registry is available to monitor pregnancy outcomes in women exposed to mepolizumab during pregnancy. ${ }^{33}$

In the clinical trial of patients aged 6-11 years, the adverse reaction profile was similar to that observed in patients aged 12 years and older. ${ }^{31}$

\section{Mepolizumab Pharmacokinetics and Route of Administration}

Mepolizumab is absorbed subcutaneously, with a central volume of distribution of about $3.6 \mathrm{~L}$ for a $70 \mathrm{~kg}$ patient. ${ }^{11} \mathrm{It}$ is metabolized by proteolytic enzymes that are present diffusely, including the liver. ${ }^{11}$ On the other hand, mepolizumab is not renally metabolized. ${ }^{11}$ The reported half-life for elimination is 16 to 22 days. ${ }^{11}$ In doses between 12.5 and $200 \mathrm{mg}$, its pharmacokinetics remain dose proportional. ${ }^{10,11}$ Mepolizumab is available in the subcutaneous form only, and is recommended to be administered in the upper arm, thigh, or abdomen. ${ }^{11}$ For severe eosinophilic asthma, a single $100 \mathrm{mg}$ injection is administered every four weeks. ${ }^{11}$ There are no dose adjustments recommended for patients with renal or hepatic impairment. ${ }^{10,11}$ The original mepolizumab preparation was manufactured in the lyophilized form in vials, which require sterile water reconstitution and injection by healthcare professionals "in-office". ${ }^{11}$ With the advent of a comparable liquid formulation, ${ }^{34}$ mepolizumab gained FDA approval in June 2019 for two new, "at-home" methods of selfadministration either as an autoinjector (AI) or as a pre-filled safety syringe. ${ }^{11}$ Real-world data from 2 open-label single-arm phase 3a studies ${ }^{35,36}$ showed that patients with severe eosinophilic asthma were successful at self-administering the drug both via the AI (89-95\%) and prefilled safety syringe (100\%) after receiving appropriate training from healthcare 
professionals. This makes mepolizumab unique, in that it is the first anti-IL5 biologic to be licensed in the US for at-home administration, and the first respiratory biologic to be approved for administration via an autoinjector. ${ }^{37}$

\section{Severe Asthma Clinic Experiences University of California, Davis Asthma Network Clinics (UCAN ${ }^{\mathrm{TM}}$ ) \\ Program Overview}

The approach at UC Davis to difficult-to-control asthma (Asthma Control Test [ACT] score $<20$ after 3 months of adherence to ICS plus LABA) requires first ascertaining the diagnosis of asthma is correct. ${ }^{38}$ We exclude other common diagnoses mimicking asthma, for example, gastroesophageal reflux disease (GERD), vocal cord dysfunction, asthma-COPD overlap syndrome (ACOS). We also identify confounding co-morbidities such as gastroesophageal reflux disease (GERD), obstructive sleep apnea (OSA), and use of drugs including beta-blockers and angiotensin-converting enzyme inhibitors, even if this is the third or fourth evaluation (Figure 4). The GINA guidelines are reviewed every year to reflect new knowledge and practice experience. ${ }^{8,39}$

After re-evaluation of the diagnosis of asthma, we attempt to understand the asthma phenotype by clinical presentation or patient appearance. Examples include allergic (extrinsic) or non-allergic (intrinsic), age stratification (early onset or late onset, less than or greater than 40 years old), lung function (fixed airway obstruction, FEV1 $<80 \%$ predicted), and response to inhaled or systemic corticosteroids within their current asthma action plan after a required evaluation of their inhaler technique (Table 2).

Endotyping is done next to establish whether the patient's asthma is T2-high or T2-low. Measuring biologic markers, specifically serum total IgE and ImmunoCap $^{\circledR}$ panel to detect atopy, perennial aeroallergens (dust mites, cockroach, pet dander), and fungal sensitivities, and FeNO provide valuable clues. A complete blood count with differential will yield peripheral blood eosinophil numbers which can further group patients into eosinophilic or non-eosinophilic (dominant cell neutrophils, mixed inflammatory granulocytes, or paucigranulocytic) endotypes based on peripheral eosinophil count. ${ }^{40}$ A peripheral eosinophil count of at least 150 cells $/ \mu \mathrm{L}$ is considered clinically significant if the patient is on moderate to high-dose ICS and/or any dosage of prednisone or methylprednisolone. Non-

\section{UC Davis ASTHMA NETWORK (UCAN) DIFFICULT-TO-CONTROL ASTHMA TREATMENT AND REFERRAL}

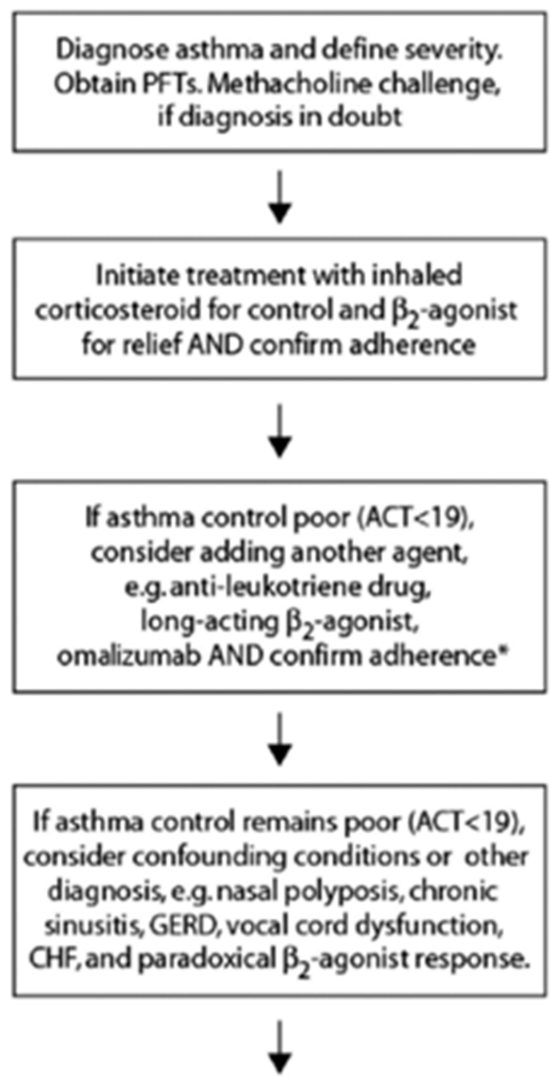

Refer to Asthmatologist if control not achieved in 2 to 3 months 1) Pulmonologist (? abnormal CT scan, ? COPD, ? ABPA, ?sarcoidosis, ? vocal cord dysfunction,? pulmonary hypertension)

2) Allergist (? allergic rhinitis, ? immunotherapy,? Churg-Strauss) 3) Internist/Family Practitioner with asthma experience or Gastroenterologist (? GERD,? CHF)

4) Otolaryngologist (? chronic sinusitis, ? vocal cord dysfunction)

Figure 4 Difficult-to-control asthma treatment and referral process at UC Davis Asthma Network.

Abbreviations: PFT, pulmonary function test; $A C T$, asthma control test; $A B P A$, allergic bronchopulmonary aspergillosis: GERD, gastroesophageal reflux disease: CHF congestive heart failure.

allergic phenotype tends to be associated with obesity and late-onset phenotype with female gender. Other important asthma endotypes include aspirin-exacerbated respiratory disease and allergic bronchopulmonary mycosis.

This initial screening of the asthma patient's phenotype and endotype can be achieved readily in a primary care clinic by ordering these biomarkers before consultation with an asthmatologist. Our experience is that a referral clinic dedicated to difficult-to-control asthma promotes patient education, correct inhaler technique, patient safety, 
Table 2 Asthma Phenotypes and Endotypes

\begin{tabular}{|l|}
\hline Asthma Phenotypes \\
\hline Allergic asthma \\
Non-allergic asthma \\
Asthma with obesity \\
Asthma with fixed airway disease \\
Asthma with late onset \\
\hline Asthma endotypes \\
T2-high, including IgE-mediated asthma and immunogenesis from \\
IL-4, IL-5, IL-9, IL-I3 \\
T2-low, including IL-5, IL-I3 \\
Eosinophilic with peripheral blood eosinophils $\geq 150$ to 300 cells/ $\mu \mathrm{L}$ \\
Non-eosinophilic, including neutrophilic, mixed, and paucigranulocytic \\
\hline
\end{tabular}

Notes: Data from Global Initiative for Asthma. Global Strategy for Asthma Management and Prevention. $2020^{8}$

and clinical outcomes favorable to both patients and the healthcare institution.

In the truly difficult-to-control asthmatic, we would consider a chest $\mathrm{CT}$ for bronchiectasis, hypersensitivity pneumonitis, interstitial lung disease, or venous thromboembolism if the diffusion capacity of the lungs for carbon monoxide (DLco) is abnormally low ( $<80 \%$ predicted). It is important to consider fiberoptic bronchoscopy with bronchoalveolar lavage, endobronchial and transbronchial biopsies if the diagnosis of sarcoidosis is a possibility. If we find a positive serology for Aspergillus species or other fungus in the right clinical situation, we consider treatment for 8 months with itraconazole $200 \mathrm{mcg}$ twice daily. ${ }^{40}$ If we want to truly assess corticosteroid responsiveness, we treat the patient with 12 days of prednisone (eg, $40 \mathrm{mg} \times 3$ days, $30 \mathrm{mg} \times 3$ days, $20 \mathrm{mg} \times 3$ days, $10 \mathrm{mg} \mathrm{x} 3$ days), often in the late afternoon rather than the morning, and have the patient return to clinic to determine if his or her asthma is refractory to corticosteroids. A favorable response to ICS, for example, improvement in symptoms and spirometry (FEV1 increase by $>5 \%$ ), would drive us to consider add-on maintenance therapies in addition to high-dose ICS and LABA, as outlined in Step 5 of the GINA 2019 guide (Figure 1) ${ }^{8,9}$ In our clinic experience, the majority of our asthma patients fulfill the severe asthma definition and need daily OCS in addition to high-dose ICS to control symptoms. ${ }^{5}$

Five asthma biologic monoclonal antibodies are available for prescription when considering Step 5 GINA 2020 recommended therapies (Tables 1 and 3). In alphabetical order, these biologics include benralizumab, which targets IL5R $\alpha$, dupilumab which targets IL4R $\alpha$, mepolizumab and reslizumab which target circulating IL-5, and omalizumab which targets circulating IgE (Figure 2). We monitor patients receiving omalizumab or any patient with a history of anaphylaxis regardless of the biologic prescribed in clinic for anaphylaxis for 2 hours the first 3 injections (captures $77 \%$ of anaphylactic reactions) and would discontinue if there is no clinical benefit after 3 to 4 months of asthma control assessment. ${ }^{41,42}$ At UC Davis, we additionally offer bronchial thermoplasty to both T2-high and T2-low asthmatics who are not interested in prolonged injectable biologic treatments or their adverse effects and to patients who failed to improve on asthma biologics. ${ }^{43}$

\section{Patient Acceptance and Usability of Self-Administered Medications}

Acceptance and adherence of self-administered medications have been surprisingly higher in our clinical practice after taking the time to review each patient's "life-markers. "It is during that initial discussion that patients can express if they feel uncomfortable or are uncertain if they can appropriately inject themselves. If patients still feel insecure or uncomfortable after the first supervised self-administration of mepolizumab, we will transition medication administration to be done only in the clinic. Patients are also given the option to bring in their autoinjector, so they could be supervised as they self-inject until they feel comfortable doing it at home. Once Mepolizumab received FDA approval for its AI on June 2019, patients who were receiving their mepolizumab injection in clinic were informed that they would now have the option to switch to home autoinjector. Interestingly, less than a third of our current in-clinic mepolizumab patients were willing to switch over to home injection while the remaining patients preferred nonautoinjector in-clinic injections. Nevertheless, having the option to perform biologic injections at home has now provided a way for patients with certain barriers (eg, lack of transportation, residing extremely far from clinic) to receive injections more consistently.

At UC Davis, we have developed best practices for athome self-administration of biologics by patients or caregivers. This is founded on patient education on proper use and administration of AIs and regular review of important safety information including adverse events that can occur at home. A concierge service is provided to patients by pager every day, or a scheduled video visit from a team consisting of a UCAN registered respiratory therapist (RRT) and an asthmatologist who is a pulmonologist at UC Davis. 
Table 3 Biologics for Uncontrolled Severe Asthma

\begin{tabular}{|c|c|c|c|c|c|}
\hline & Omalizumab & Mepolizumab & Reslizumab & Benralizumab & Dupilumab \\
\hline $\begin{array}{l}\text { Mechanism of } \\
\text { Action }\end{array}$ & Anti-lgE & Anti-IL-5 & Anti-IL-5 & Anti-IL5R $\alpha$ & Anti-IL4R $\alpha$ \\
\hline Dosing In-Office & $\begin{array}{l}75 \text { to } 375 \mathrm{mg} \mathrm{SC} \\
\text { every } 2 \text { to } 4 \text { weeks }\end{array}$ & $\begin{array}{l}\text { I00 mg SC every } 4 \\
\text { weeks }\end{array}$ & $\begin{array}{l}3 \mathrm{mg} / \mathrm{kg} \text { IV every } 4 \\
\text { weeks }\end{array}$ & $\begin{array}{l}30 \mathrm{mg} \text { SC every } 4 \\
\text { weeks then every } 8 \\
\text { weeks }\end{array}$ & $\begin{array}{l}200 \mathrm{mg} \text { or } 300 \mathrm{mg} \\
\text { every } 2 \text { weeks }\end{array}$ \\
\hline Dosing At-Home & $N / A$ & $\begin{array}{l}\text { I00 mg SC every } 4 \\
\text { weeks by } \\
\text { autoinjector }\end{array}$ & $\mathrm{N} / \mathrm{A}$ & $\begin{array}{l}30 \mathrm{mg} \mathrm{SC} \text { every } 8 \\
\text { weeks by autoinjector }\end{array}$ & $\begin{array}{l}300 \text { mg every } 2 \\
\text { weeks by pre-filled } \\
\text { syringe }\end{array}$ \\
\hline $\begin{array}{l}\text { Anaphylaxis } \\
\text { warning }\end{array}$ & Yes & No & Yes & No & No \\
\hline $\begin{array}{l}\text { Age (years) } \\
\text { Eligibility }\end{array}$ & Age $\geq 6$ & Age $\geq 6$ & Age $\geq 18$ & Age $\geq 12$ & Age $\geq 12$ \\
\hline $\begin{array}{l}\text { Asthma severity } \\
\text { (NAEPP 2007) }\end{array}$ & $\begin{array}{l}\text { Moderate to Severe } \\
\text { Persistent }\end{array}$ & Severe Persistent & Severe Persistent & Severe Persistent & $\begin{array}{l}\text { Moderate to Severe } \\
\text { Persistent }\end{array}$ \\
\hline $\begin{array}{l}\text { Severe Asthma } \\
\text { diagnosis (GINA } \\
\text { 2019) }\end{array}$ & $\begin{array}{l}\text { Yes Requiring Step } 4 \\
\text { or Step } 5\end{array}$ & $\begin{array}{l}\text { Yes Requiring Step } 4 \\
\text { or Step } 5\end{array}$ & $\begin{array}{l}\text { Yes Requiring Step } 4 \text { or } \\
\text { Step } 5\end{array}$ & $\begin{array}{l}\text { Yes Requiring Step } 4 \\
\text { or Step } 5\end{array}$ & $\begin{array}{l}\text { Yes Requiring Step } 4 \\
\text { or Step } 5\end{array}$ \\
\hline Standard of Care & $\begin{array}{l}\text { Medium to High-dose } \\
\text { ICS } \pm \text { other controller }\end{array}$ & $\begin{array}{l}\text { High-dose ICS + } \\
\text { LABA or LTRA }\end{array}$ & $\begin{array}{l}\text { Medium to High-dose } \\
\text { ICS } \pm \text { another } \\
\text { controller }\end{array}$ & $\begin{array}{l}\text { Medium to High-dose } \\
\text { ICS + LABA }\end{array}$ & $\begin{array}{l}\text { Medium to High- } \\
\text { dose ICS + LABA }\end{array}$ \\
\hline $\begin{array}{l}\text { Daily OCS } \\
\text { accepted }\end{array}$ & Yes & Yes & Yes & Yes & No \\
\hline $\begin{array}{l}\text { Exacerbation } \\
\text { history past } 12 \\
\text { months }\end{array}$ & N/A & $\geq 2$ & $\geq 1$ & $\geq 2$ & $\geq 1$ \\
\hline Atopy required & Yes & No & No & No & No \\
\hline IgE level (IU/mL) & 30 to $700 \mathrm{IU} / \mathrm{Ml}$ & N/A & $\mathrm{N} / \mathrm{A}$ & N/A & N/A \\
\hline $\begin{array}{l}\text { Eosinophil count } \\
\text { (cells/mm3) }\end{array}$ & $N / A$ & $\begin{array}{l}\geq 150 \text {, or } \geq 300 \text { in } \\
\text { past year }\end{array}$ & $\geq 400$ & $\begin{array}{l}\text { Any or eosinophilic } \\
\text { phenotype }\end{array}$ & $\begin{array}{l}\text { Any or eosinophilic } \\
\text { phenotype }\end{array}$ \\
\hline
\end{tabular}

Abbreviations: SC, subcutaneous; IV, intravenous; N/A, not available; ICS, inhaled corticosteroids; LABA, long-acting beta2-agonist; LTRA, leukotriene receptor antagonist; OCS, oral corticosteroids; NAEPP, National Asthma Education and Prevention Program; GINA, Global Initiative for Asthma 497.

We employ a patient safety checklist for determining whether the biologic prescribed such as mepolizumab is appropriate based on phenotype and endotype, effective (well-controlled asthma only, Asthma Control Test (ACT) $\geq 20$, no report of adverse reactions, or physician decision), and well tolerated for a patient to self-administer a biologic at home. Each case is assessed and all eight questions on the checklist must be answered YES before the at-home injection/administration option with a biologic can proceed (Table 4).

This process of transitioning from in-office to at-home administration requires experienced providers who are familiar with the biologics, the disease being treated, the preparation process prior to administration, and the actual injection. For example, we provide proper training on the mepolizumab autoinjector preparation, administration, and specific injection techniques using Instruction for $\mathrm{Use}^{44}$ provided by GlaxoSmithKline.

We have recently employed video visits for patients participating in the at-home injection program to assess asthma control and review response to the biologic.

Clinical monitoring for complications from drug injection and mitigation of risks unique to the individual patient are best achieved when biologics are injected in a clinic 
Table 4 Checklist to Qualify for UCAN at-Home Injection Program

\section{All Questions Must Be Answered YES for a Patient to Qualify for Program}

I. Diagnosis of asthma is correct?

2. Phenotype and endotype is correct?

3. Asthma is well-controlled or best control achieved?

That is Asthma Control Test (ACT) $\geq 20$ or attainment of the best control possible $(\mathrm{ACT}<20)$ or at least 3 months on a biologic (exception with dupilumab which is discouraged by insurers from being administered in office) and standard of care treatments, ie ICS + $\mathrm{LABA} \pm$ additional controller

4. Absence of adverse events or side effects attributable to biologic drug?

5. Patient prefers at-home injection?

6. Absence of hypersensitivity reactions and/or anaphylaxis after 3 months of clinic administration of asthma biologic (exception with dupilumab)?

7. Anticipated medication adherence and compliance with at-home administration is good?

8. Competence confirmed using the patient teach-back method in clinic to assess a patient's competence in employing the necessary knowledge and technique self- administer biologics at home, including storage, checking for expiration date, selection and rotation of injection sites, and proper disposal after use?

Abbreviations: UCAN, University of California, Asthma Network; ACT, Asthma Control Test; ICS, inhaled corticosteroids; LABA, long-acting beta2-agonist.

supervised by on-site physicians who can respond to serious adverse reactions, including life-threatening anaphylaxis. Patients typically receive their first three months of treatment in the clinic (with the exception of dupilumab).

Medication adherence refers to whether patients take their medications as prescribed, eg, once a month, once every two weeks, or once every eight weeks. There is no gold standard for measuring medication adherence. The relationship between the clinic and patient, as well as access to our UCAN RRT and/or asthmatologists when questions arise, is vital in optimizing adherence. Non-adherence or non-compliance is a major problem and can consist of patient failing to take their prescribed medications as prescribed, not injecting incorrectly, or forgetting/failing to refill the biologic prescription regularly. This can be minimized by having only a one-month supply of the biologic filled at a time. It can also be requested that the specialty pharmacy involved notifying the clinician if the patient is not picking up their biologic as prescribed.

Our experience from the in-clinic injection program provides the clinical response and frequency of acute exacerbations that is expected with at-home injection in patients with severe asthma. We recommend that patients visit clinic quarterly or every three months for the first year, then at least every six to 12 months (or sooner as necessary). A potentially harmful problem in ten to $15 \%$ of our patients on asthma biologics is self-discontinuation of some or all of their other daily asthma medications, including OCSs. Patients might fail to notify the clinic about stopping standard of care treatments if they become convinced that the biologic is a miracle drug after their persistent asthma symptoms improve dramatically or their need for albuterol disappears. All patients must be warned to not discontinue systemic or inhaled corticosteroids abruptly upon initiation of any biologic therapy. Decreases in corticosteroid doses, if appropriate, should be gradual and under the direct supervision of a physician. Reduction in systemic corticosteroid dose may be associated with withdrawal symptoms and/or unmask conditions previously suppressed by OCS therapy, such as Churg-Strauss syndrome.

Authorizations from healthcare insurers are typically issued for 12 months. Each clinic team must regularly document office visit assessments for asthma control, as well as annual re-assessment to determine if continuation of the biologic is medically necessary. Chart notes, laboratory data, and consultation documentation are typically submitted for initial prior authorization and for continuation of treatment at least once annually. Peer-to-peer review is a common occurrence with any request for authorization.

To maintain authorization from the healthcare insurer, the physician or provider must document effectiveness as evidenced by improvement in asthma control with the addon biologic after initial therapy, whether in-office or athome. Improvement can be measured with the Asthma Control Test (ACT) score by an increase at least 3 points or more, score $\geq 20$ or attainment of the best control possible under the prevailing circumstances, decrease in need for daily prednisone or bursts, decrease in need for albuterol, or decrease in need for urgent care, or emergency department visits and/or hospitalization for uncontrolled asthma. Discontinuation of treatment should be a joint decision between the patient and the physician or asthmatologist whether in office or at home (Table 5).

\section{Loma Linda University Asthma Clinic Program Overview}

Before the selection and administration of mepolizumab, a thorough discussion with the patient should be performed. Like the practices at the UC Davis, at Loma Linda University Health (LLUH), we review the inflammatory profile and discuss the meaning of biomarkers with 
Table 5 Indications for Discontinuation of Treatment at UCAN at-Home Injection Program

\begin{tabular}{l} 
Discontinuation of at-Home Administration is Indicated if \\
Any of the Following Events or Condition Applies \\
\hline I. Intolerance to biologic, eg persistent headache, nausea \\
2. Poor adherence or compliance with treatment that is \\
uncorrectable \\
3. Poor response to treatment, ie decline in asthma control, increase \\
in symptoms and/or acute exacerbations \\
4. Hypersensitivity and/or anaphylaxis to the biologic or any excipient \\
of the formulation
\end{tabular}

Abbreviation: UCAN, University of California, Asthma Network.

each patient. We then proceed to go beyond the biomarkers and explore the patient's "life-markers." Synonymous with shared decision-making (SDM), "life-markers" comprise the patient's needs, values and preferences. By intentionally going beyond the patient's biomarkers and addressing the patient's "life-markers," we can choose the best biologic treatment plan with the aim of improving patient satisfaction and overall outcome. ${ }^{45}$

Addressing each patient's life-marker also provides insight on whether administration in office or at home injection is the preferred route. Mepolizumab was initially approved as a subcutaneous in-office injection add-on treatment for patients with uncontrolled severe eosinophilic asthma and for patients with eosinophilic granulomatosis with polyangiitis once every four weeks. However more recently, mepolizumab liquid is also now available in a ready-to-use single-use prefilled autoinjector or safety syringe that allows patients (or their caregivers) to administer the drug at home every four weeks.

For patients who prefer home injection mepolizumab use, the first injection is typically supervised under the guidance of a healthcare provider. The designated healthcare provider at LLUH is our biologic nurse that supervises and educates the patient and/or caregiver. After reviewing how to use the autoinjector or safety syringe properly, patients are informed on the most common side effects in addition to education on potential parasitic infections and the high-risk behaviors associated with catching a parasitic infection. Our patients are provided a handout we created at LLUH on things to be aware of and avoid while being on an asthma biologic. On the handout, behaviors that increase the risk of parasitic infection in addition to signs and symptoms related to parasitic infections are highlighted. We felt that although reported parasitic infections while being on asthma biologics have been extremely rare at this time there is insufficient longitudinal data available to provide a definitive statement. ${ }^{46}$ Patients who are unable to return to the clinic for supervision for their first injection are encouraged to utilize the nurse assistance program provided by the manufacturer of mepolizumab.

\section{Best Practices with Follow-Up}

Patients are closely followed post biologic administration with a return visit scheduled as early as two months to reevaluate symptoms and adherence to the new add-on biologic medication. The time frame for medication effectiveness varies per patient, but it is our experience that improvement is typically seen within two months and if at two months there is worsening, minimal, or no improvements, reassessing medication adherence, inhaler technique and co-morbidities is performed. It is also during this timeframe that discussion and evaluation to see if switching to another asthma biologic or the addition of a non-biologic (ie, bronchial thermoplasty) treatment should be attempted at the end of four months. 5,47

\section{Conclusion}

With an increased understanding of asthma phenotypes and endotypes comes a more individualized treatment plan for patients with severe asthma. Specifically, in patients with severe eosinophilic asthma, biologic therapy such as mepolizumab has been shown to be beneficial in reducing exacerbation rates. ${ }^{18}$ In addition, a benefit to mepolizumab is its availability as easy-to-use subcutaneous autoinjectors or prefilled syringes that can be administered at home by the patients themselves or by their caregivers. ${ }^{48,49}$ UC Davis and Loma Linda University Health have both incorporated homeinjection programs within the asthma clinics, with individualized discussions with patients about clinic-to-home transitions based off of not only their disease state but also their "lifemarkers." Programs like these can not only ultimately lead to decreased healthcare costs by reducing clinic visits but also allow patients with barriers to receiving in-clinic injections to obtain their biologic doses more consistently. The presence of an asthma clinic with organized home-injection training and follow-up protocols can also be helpful in overcoming barriers to self-administration by improving patient acceptance and usability of these medications.

\section{Disclosure}

SL is a consultant and speaker for AstraZeneca, Genentech, GlaxoSmithKline, Regeneron, and Sanofi Genzyme. LT reports personal fees from AstraZeneca, Sanofi, Regeneron, Boehringer Ingelheim, and Genentech, outside the submitted 
work. The authors report no other conflicts of interest in this work.

\section{References}

1. Flores KF, Bandoli G, Chambers CD, Schatz M, Palmsten K. Asthma prevalence among women aged 18 to 44 in the United States: national health and nutrition examination survey 2001-2016. J Asthma. 2019;1-10.

2. California Breathing County Asthma Data Tool. California Department of Public Health; 2019. Available from: www.cdph.ca.gov/Programs/ C C D P H P / D E O D C / E H I B / C P E / P a g e s / CaliforniaBreathingCountyAsthmaProfiles.aspx. Accessed May 20, 2020

3. Lam J, Hay JW, Salcedo J, Kenyon NJ. A cost-effectiveness analysis of reslizumab in the treatment of poorly controlled eosinophilic asthma. J Asthma. 2019;56(8):872-881. doi:10.1080/02770903.2018.1500584

4. Carr TF, Zeki AA, Kraft M. Eosinophilic and Noneosinophilic Asthma. Am J Respir Crit Care Med. 2018;197(1):22-37. doi:10.1164/rccm.201611-2232PP

5. Chung KF, Wenzel SE, Brozek JL, et al. International ERS/ATS guidelines on definition, evaluation and treatment of severe asthma. Eur Respir J. 2014;43(2):343-373. doi:10.1183/ 09031936.00202013

6. Woodruff PG, Modrek B, Choy DF, et al. T-helper type 2-driven inflammation defines major subphenotypes of asthma. Am J Respir Crit Care Med. 2009;180(5):388-395. doi:10.1164/rccm.200903-0392OC

7. Global Initiative for Asthma. Global Strategy for Asthma Management and Prevention; 2017.

8. Global Initiative for Asthma. Global Strategy for Asthma Management and Prevention; 2020.

9. Martin RJ, Szefler SJ, King TS, et al. The Predicting Response to Inhaled Corticosteroid Efficacy (PRICE) trial. J Allergy Clin Immunol. 2007;119(1):73-80. doi:10.1016/j.jaci.2006.10.035

10. Johnson N, Varughese B, De La Torre MA, Surani SR, Udeani G. A review of respiratory biologic agents in severe asthma. Cureus. 2019;11(9):e5690. doi:10.7759/cureus.5690

11. Mepolizumab [package insert]. Philadelphia, PA: GlaxoSmithKline LLC; 2019.

12. Farne HA, Wilson A, Powell C, Bax L, Milan SJ. Anti-IL5 therapies for asthma. Cochrane Database Syst Rev. 2017;9:Cd010834.

13. Drick N, Seeliger B, Welte T, Fuge J, Suhling H. Anti-IL-5 therapy in patients with severe eosinophilic asthma - clinical efficacy and possible criteria for treatment response. BMC Pulm Med. 2018;18 (1):119. doi:10.1186/s12890-018-0689-2

14. Haldar P, Pavord ID, Wardlaw AJ. Insights into the Pathogenesis of Asthma and Other Eosinophil-Mediated Diseases from Antagonists of Interleukin-5 and its ReceptorIn Chapter 15 - Antieosinophil Therapeutics. In: Lee JJ, Rosenberg HF, editors. Eosinophils in Health and Disease. Boston: Academic Press; 2013:577-605.

15. Varricchi G, Canonica GW. The role of interleukin 5 in asthma. Expert Rev Clin Immunol. 2016;12(9):903-905. doi:10.1080/ 1744666X.2016.1208564

16. Kouro T, Takatsu K. IL-5- and eosinophil-mediated inflammation: from discovery to therapy. Int Immunol. 2009;21(12):1303-1309. doi:10.1093/intimm/dxp102

17. Possa SS, Leick EA, Prado CM, Martins MA, Tibério IFLC. Eosinophilic inflammation in allergic asthma. Front Pharmacol. 2013;4:46. doi:10.3389/fphar.2013.00046

18. Bel EH, Wenzel SE, Thompson PJ, et al. Oral glucocorticoid-sparing effect of mepolizumab in eosinophilic asthma. $N$ Engl $J$ Med. 2014;371(13):1189-1197. doi:10.1056/NEJMoa1403291

19. Pavord ID, Chanez P, Criner GJ, et al. Mepolizumab for eosinophilic chronic obstructive pulmonary disease. $N$ Engl J Med. 2017;377 (17):1613-1629. doi:10.1056/NEJMoa1708208
20. Efficacy and safety study of mepolizumab in subjects with severe hypereosinophilic syndrome (HES); Identifier NCT02836496. ClinicalTrialsgov. Bethesda, MD: National Library of Medicine, US; July 19, 2016.

21. Effect of mepolizumab in severe bilateral nasal polyps, Identifier NCT03085797. ClinicalTrialsgov. Bethesda, MD: National Library of Medicine (US); March 21, 2017.

22. Fajt ML, Wenzel SE. Development of New Therapies for Severe Asthma. Allergy Asthma Immunol Res. 2017;9(1):3-14. doi:10.4168/aair.2017.9.1.3

23. Pavord ID, Korn S, Howarth P, et al. Mepolizumab for severe eosinophilic asthma (DREAM): a multicentre, double-blind, placebo-controlled trial. Lancet. 2012;380(9842):651-659. doi:10.1016/S0140-6736(12)60988-X

24. Ortega HG, Liu MC, Pavord ID, et al. Mepolizumab treatment in patients with severe eosinophilic asthma. $N$ Engl J Med. 2014;371 (13):1198-1207. doi:10.1056/NEJMoa1403290

25. Chupp GL, Bradford ES, Albers FC, et al. Efficacy of mepolizumab add-on therapy on health-related quality of life and markers of asthma control in severe eosinophilic asthma (MUSCA): a randomised, double-blind, placebo-controlled, parallel-group, multicentre, phase 3b trial. Lancet Respir Med. 2017;5(5):390-400. doi:10.1016/S2213-2600(17)30125-X

26. Kerr W, Harrison T, Loveday K, et al. P92 Effectiveness and safety of mepolizumab in real-world clinical practice: UK patient outcomes from the REALITI-A study. Horax. 2019;74:A140.

27. Khatri S, Moore W, Gibson PG, et al. Assessment of the long-term safety of mepolizumab and durability of clinical response in patients with severe eosinophilic asthma. J Allergy Clin Immunol. 2019;143 (5):1742-1751.e1747. doi:10.1016/j.jaci.2018.09.033

28. Pouliquen IJ, Kornmann O, Barton SV, Price JA, Ortega HG. Characterization of the relationship between dose and blood eosinophil response following subcutaneous administration of mepolizumab. Int $J$ Clin Pharmacol Ther. 2015;53(12):1015-1027. doi:10.5414/CP202446

29. Cessation versus continuation of long-term mepolizumab in severe eosinophilic asthma patients, Identifier NCT02555371. ClinicalTrialsgov. Bethesda, MD: National Library of Medicine (US); September 21, 2015.

30. A Phase 3a, repeat dose, open-label, long-term safety study of mepolizumab in asthmatic subjects, Identifier NCT02135692. ClinicalTrialsgov Bethesda, MD: National Library of Medicine (US); May 12, 2014.

31. Safety profile - Mepolizumab for severe eosinophilic asthma. Available from: https://gskprocom/en-us/products/nucala/for-severeeosinophilic-asthma/safety/. Accessed May 19, 2020.

32. Summary of product characteristics (SmPC): mepolizumab (Nucala) $100 \mathrm{mg}$ solution for injection in pre-filled syringe. EMC Electronic Medicines Compendium, UK. Available from: https://wwwmedicine sorguk/emc/product/10564/smpc. Accessed May 19, 2020.

33. MotherToBaby pregnancy exposure registry. Available from: https:// mothertobabyorg/ongoing-study/asthma/. Accessed May 19, 2020.

34. A study to compare the pharmacokinetics of mepolizumab as a drug in a safety syringe or an autoinjector versus lyophilised drug, Identifier NCT03014674. ClinicalTrialsgov. Bethesda, MD: National Library of Medicine (US); January 9, 2017

35. Study of mepolizumab autoinjector in asthmatics, Identifier NCT03099096. ClinicalTrialsgov. Bethesda, MD: National Library of Medicine (US) April 4, 2017.

36. Study of mepolizumab safety syringe in asthmatics, Identifier NCT03021304. ClinicalTrialsgov. Bethesda, MD: National Library of Medicine (US); January 13, 2017.

37. Nucala (mepolizumab) gains FDA approval for two new selfadministration options. GSK Press Releases; June 06, 2019. Available from: https://wwwgskcom/en-gb/media/press-releases /nucala-mepolizumab-gains-fda-approval-for-two-new-selfadministration-options. Accessed May 19, 2020.

38. Mealey FH, Kenyon NJ, Avdalovic MV, Louie S. Difficult-to-control asthma in adults. Am J Med. 2007;120(9):760-763. doi:10.1016/j. amjmed.2006.10.015 
39. Reddel HK, FitzGerald JM, Bateman ED, et al. GINA 2019: a fundamental change in asthma management: treatment of asthma with short-acting bronchodilators alone is no longer recommended for adults and adolescents. Eur Respir J. 2019;53(6):1901046. doi:10.1183/13993003.01046-2019

40. Denning DW, O’Driscoll BR, Powell G, et al. Randomized controlled trial of oral antifungal treatment for severe asthma with fungal sensitization: the Fungal Asthma Sensitization Trial (FAST) study. Am J Respir Crit Care Med. 2009;179(1):11-18. doi:10.1164/ rccm.200805-7370C

41. Cox L, Lieberman P, Wallace D, et al. American Academy of Allergy, Asthma \& Immunology/American College of Allergy, Asthma \& Immunology Omalizumab- Associated Anaphylaxis Joint Task Force follow-up report. J Allergy Clin Immunol. 2011;128 (1):210-212. doi:10.1016/j.jaci.2011.04.010

42. Cox L, Platts-Mills TA, Finegold I, Schwartz LB, Simons FE, Wallace DV. American Academy of Allergy, Asthma \& Immunology/American College of Allergy, Asthma and Immunology Joint Task Force Report on omalizumab-associated anaphylaxis. J Allergy Clin Immunol. 2007;120(6):1373-1377. doi:10.1016/j.jaci.2007.09.032
43. Tan LD, Kenyon N, Yoneda KY, Louie S. Bronchial thermoplasty: implementing best practice in the era of cost containment. J Asthma Allergy. 2017;10:225-230. doi:10.2147/JAA.S135291

44. Prefilled Autoinjector: Instructions for Use - Nucala (mepolizumab) $100 \mathrm{mg} / \mathrm{mL}$ injection. Nucala website Available from: https:/wwwnuca lacom/content/dam/cf-pharma/nucala-v2/en_US/sea/pdf/NUCALA_ Autoinjector_Instructions_for_Use.pdf. Accessed May 19, 2020.

45. Tan L, Chupp G, Castro M, Kraft M. Going Beyond "Bio-markers", Think “Life- markers". CHEST. 2020;157(3):503-505. doi:10.1016/j. chest.2019.08.2210

46. Tan LD, Schaeffer B, Alismail A. Parasitic (Helminthic) infection while on asthma biologic treatment: not everything is what it seems. J Asthma Allergy. 2019;12:415-420. doi:10.2147/JAA.S223402

47. Rogliani P, Calzetta L, Matera MG, et al. Severe asthma and biological therapy: when, which, and for whom. Pulm Ther. 2019.

48. Bel EH, Bernstein DI, Bjermer L, et al. Usability of mepolizumab single-use prefilled syringe for patient self-administration. J Asthma. 2019;1-10.

49. Bernstein D, Pavord ID, Chapman KR, et al. Usability of mepolizumab single-use prefilled autoinjector for patient self-administration. J Asthma. 2019:1-12. doi:10.1080/02770903.2019.1630641

\section{Publish your work in this journal}

Patient Preference and Adherence is an international, peer-reviewed, open access journal that focusing on the growing importance of patient preference and adherence throughout the therapeutic continuum. Patient satisfaction, acceptability, quality of life, compliance, persistence and their role in developing new therapeutic modalities and compounds to optimize clinical outcomes for existing disease states are major areas of interest for the journal. This journal has been accepted for indexing on PubMed Central. The manuscript management system is completely online and includes a very quick and fair peer-review system, which is all easy to use. Visit http:// www.dovepress.com/testimonials.php to read real quotes from published authors. 